\title{
Formulation and evaluation of lamivudine sustained release tablet using okra mucilage
}

\author{
Narahari N. Palei*, Santhosh K. Mamidi, Jayaraman Rajangam \\ Sree Vidyanikethan College of Pharmacy, Tirupati, Andhra Pradesh., Avanthi Institute of Pharmaceutical Sciences, Vizianagaram, Andhra Pradesh, India.
}

\section{ARTICLE INFO}

Article history:

Received on: 28/04/2016

Revised on: 19/05/2016

Accepted on: 12/06/2016

Available online: 26/09/2016

Key words:

Lamivudine, Okra mucilage,

sustained release, matrix

tablet.

\begin{abstract}
The present study was to extract the mucilage from the Okra plant (Abelmoschus esculentus) and to study the effect of mucilage concentration on in vitro release of Lamivudine from it's sustained release matrix tablets. Mucilage was extracted from the fruits of Abelmoschus esclentus using organic solvent Acetone. The extracted mucilage was subjected to various physiological properties for its suitability as an excipient in the preparation of tablet. Lamivudine sustained release tablets were prepared using different concentration of Okra mucilage as a sustained release matrix excipient. The formulated tablets were evaluated for post compression parameters such as weight variation, hardness, friability, wetting time, water absorption ratio, and in vitro drug release studies. Stability studies of optimized formulation were carried out for three months. The results of in vitro release revealed that the release rate decreased with increase in the concentration of mucilage. The release kinetics indicated that the nature of drug release from the matrix tablets was dependent on drug diffusion and polymer relaxation and therefore followed non-fickian or anomalous release. No incompatibility was observed between the drug and excipients used in the formulation of matrix tablets. The Okra mucilage showed promising results in terms of sustaining the release behavior of Lamivudine from the matrix. The developed sustained release tablets of Lamivudine, with extension of release up to 12 hours, can overcome all the disadvantages of conventional Lamivudine tablets.
\end{abstract}

\section{INTRODUCTION}

In recent years, plant gums and mucilages have evoked tremendous interest due to their diverse pharmaceutical applications such as diluents, binders, disintigrants in tablet, thickener in oral liquid, protective colloids in suspensions and gelling agent in gels (Singh et al., 2009; Ameena et al., 2010). Polysaccharides are obtained from plants that could be applied in various pharmaceutical products. Okra mucilage from the pods of Abelmoschus esculentus is currently being studied in the pharmaceutical industry as a hydrophilic polymer in pharmaceutical dosage forms. The Okra is a bulky annual plant cultivated throughout the tropical and subtropical areas of the

* Corresponding Author

Narahari N Palei, Sree Vidyanikethan College of Pharmacy,

Tirupati, Andhra Pradesh, India.mail id:narahari.palei@gmail.com world, particularly in India. The fresh green pods are rich in mucilage. Okra is widely harvested and does not require toxicology studies. It has been investigated as a binding agent for tablets and has also been shown to produce tablets with good hardness, friability, and drug release profiles (Okoye et al., 2011). Natural materials have advantages over synthetic materials because they are non toxic, less expensive and freely available. It has advantages over most commercial synthetic polymers as it is safe, chemically inert, non irritant, biodegradable, biocompatible, and eco-friendly (Malviya et al., 2011). Mucilages serve as food reserve and membrane thickener and aid in water storage and seed germination. Okra mucilage contains polysaccharides such as galactose, galacturonic acid, rhamnose and when extracted in water these polysaccharides produce highly viscous solution. Therefore, the highly viscous property of Okra mucilage may be useful as a retarding polymer in the formulation of sustained release tablets (Zaharuddin et al., 2014). 
In the present work, we have isolated and characterized Okra mucilage and evaluated its sustained-release properties employing Lamivudine as a model drug. Lamivudine has been used for the treatment of AIDS and chronic Hepatitis B. Lamivudine conventional formulations are administered multiple times a day (150 mg twice daily) because of its moderate half-life $\left(\mathrm{t}_{1 / 2}=5-7\right.$ hours $)$. Treatment of AIDS using Lamivudine conventional formulations is shown adverse side effects resulting from accumulation of drug in multidose therapy, poor patient compliance, and high cost. Therefore Lamivudine sustained release formulation can overcome some of these problems (Moyle et al., 2007; Punna et al., 2003). The matrix tablets of Lamivudine were formulated using wet granulation method and evaluated for weight variation, swelling behavior, hardness, friability and in vitro drug release.

\section{MATERIALS AND METHODS}

\section{Materials}

Okra fruits were obtained from the local market. Lamivudine was a gift sample from Aurobindo pharma, Hyderabad. Hydroxy propyl methyl cellulose (HPMC, E15 LV), Sodium carboxy methyl cellulose (Na CMC, Medium Viscocity grade), Microcrystalline cellulose, Starch were obtained from Loba chemie, Mumbai. Magnesium stearate was obtained from Sd fine chem, Mumbai. All chemicals are of analytical grade.

\section{Isolation of okra mucilage}

Okra mucilage was extracted from the fruits of Abelmoschus esclentus using organic solvent Acetone. The fruits of Abelmoschus esculentus were sliced into small pieces and soaked in $1000 \mathrm{ml}$ distilled water. It was boiled in a water bath for $1 \mathrm{hr}$ at $80^{\circ} \mathrm{C}$.The mucilage was separated from Abelmoschus esculentus fruits after $1 \mathrm{hr}$. Then the mucilage was precipitated from the filtrate by adding acetone. The precipitated mucilage was dried in oven at $45^{\circ} \mathrm{C}$ till it was completely dry. The mucilage was milled by using mortar and pestle. The dry powder was passed through 80 mesh sieve and stored in desiccator for further evaluation.

\section{Characterization of okra mucilage Solubility study}

Solubility of the extracted mucilage was evaluated qualitatively by stirring $10 \mathrm{mg}$ of Okra powder in $10 \mathrm{~mL}$ water, acetone, chloroform, and ethanol (1\% dispersion). Solubility was determined by visual observation of the solute.

\section{pH Determination}

$1 \% \mathrm{~W} / \mathrm{V}$ okra mucilage dispersion of the sample in water was stirred consistently for 5 minutes and $\mathrm{pH}$ was determined using a $\mathrm{pH}$ meter.

\section{Viscosity study}

Viscosity of Okra gum at $1 \%$ W/V concentrations was performed using the Brookfield viscometer (Model DV-E, U.S.A) with helipath stand. Viscosity of the mucilage dispersion was studied at a rotational speed at $10 \mathrm{rpm}$ using a S-64 spindle in triplicate.

\section{Swelling ratio}

One gram of mucilage was placed into a $25 \mathrm{ml}$ glass Stoppard measuring cylinder. $25 \mathrm{ml}$ of water was added into the cylinder containing mucilage and mixture was shaken thoroughly at intervals of every $10 \mathrm{~min}$ for $1 \mathrm{~h}$. The sample was allowed to stand for $3 \mathrm{~h}$ at room temperature and volume occupied by mucilage was measured. The mean value was calculated, related to $1 \mathrm{~g}$ of mucilage (Srinivas et al., 2003).

\section{Fourier Transform Infrared Spectroscopy (FTIR)}

FTIR spectra was recorded of pure drug, polymer (Okra mucilage), and mixture of drug with polymer. The samples were analyzed by $\mathrm{KBr}$ pellet method using FTIR spectroscopy. The spectra were scanned over a frequency range $4000-400 \mathrm{~cm}^{-1}$.

\section{Formulation of Lamivudine tablets}

The Lamivudine sustained release tablets were prepared using the wet granulation method. The granules were prepared using drug, excipients and okra mucilage powder in concentrations of $2.5 \%, 5 \%, 10 \%, 15 \%, 20 \%(\mathrm{w} / \mathrm{w})$. The moisten coherent mass was prepared and then passed through sieve no 16 and granules obtained were dried at $60^{\circ} \mathrm{C}$ for $30 \mathrm{~min}$. Magnesium stearate and talc were mixed with dried granules. The uniformly mixed blend was compressed into $450 \mathrm{mg}$ of tablets using rotary tablet compression machine. The tablets were stored in tightly closed containers. Same procedure was followed while preparing of Lamivudine sustained release tablets containing $15 \% \mathrm{w} / \mathrm{w}$ of HPMC and Na CMC as a retarding polymer (Table 1).

\section{Pre compression Parameters}

All formulations were evaluated for pre compression parameters such as angle of repose, bulk density, tapped density, Carr's consolidation index, and Hausner's ratio as per the official methods (Bi Y, 1996).

Table 1: Formulation of Lamivudine tablet containing Okra mucilage.

\begin{tabular}{|c|c|c|c|c|c|c|c|}
\hline \multirow[t]{2}{*}{ Ingredients } & \multicolumn{7}{|c|}{ Formulation Code (FC) } \\
\hline & F1 $(2.5 \%)$ & F2 $(5 \%)$ & F3 $(10 \%)$ & F4 (15\%) & F5 $(20 \%)$ & F6(15\%) & F7 $(15 \%)$ \\
\hline Lamivudine (mg) & 300 & 300 & 300 & 300 & 300 & 300 & 300 \\
\hline Okra mucilage (mg) & 11.25 & 22.5 & 45 & 67.5 & 90 & - & - \\
\hline HPMC (mg) & - & - & - & - & - & 67.5 & - \\
\hline $\mathrm{Na}$ CMC (mg) & - & - & - & - & - & - & 67.5 \\
\hline Micro crystalline cellulose (mg) & 118.75 & 107.5 & 85 & 62.5 & 40 & 62.5 & 62.5 \\
\hline Magnesium stearate (mg) & 10 & 10 & 10 & 10 & 10 & 10 & 10 \\
\hline Talc (mg) & 10 & 10 & 10 & 10 & 10 & 10 & 10 \\
\hline
\end{tabular}

Total weight of each tablet was $450 \mathrm{mg}$ : \% was mentioned on the basis of concentration of polvmer in tablet. 


\section{Post compression Parameters Weight Variation}

The weight variation test is carried out in order to ensure uniformity in the weight of the tablets in a batch. The total weight of 20 tablets from each formulation was determined and the average weight was calculated. The individual weight of the tablets was also determined accurately and the weight variation was calculated as specified in IP.

\section{Thickness}

Thickness of tablet was measured by using Vernier Calipers. Three tablets were selected at random from each batch and average measurement of three readings was taken.

\section{Hardness}

Hardness or crushing strength is the force required to break a tablet in a diametric compression which was measured using a Monsanto tablet hardness tester. It is expressed in $\mathrm{kg} / \mathrm{cm}^{2}$.

\section{Friability Test}

Friability test was carried out using Roche Friabilator. 20 tablets from each formulation were weighed and placed in Roche Friabilator rotated at $25 \mathrm{rpm}$ for 4 minutes. The tablets were dedusted and weighed again. The percentage of weight loss was calculated using the following formula (Bi YX et al., 1996):

$\%$ Friability $=\frac{[\mathrm{W} 1-\mathrm{W} 2]}{\mathrm{W} 1} \times 100$

Where ' $\mathrm{W} 1$ ' is the weight of tablet before test and ' $\mathrm{W} 2$ ' is the weight of tablet after test.

\section{Wetting Time}

Five circular tissue papers of $10 \mathrm{~cm}$ diameter were placed in a Petri dish (10 cm diameter). Ten $\mathrm{ml}$ of water containing eosin (a water soluble dye) was added to the Petri dish. A tablet was placed on the surface of the tissue paper. The time required for water to reach the upper surface of the tablet was noted (Modasiya et al., 2009).

\section{Swelling index}

Tablets were weighed individually and dispersed in 900 $\mathrm{mL}$ of the $\mathrm{pH} 6.8$, phosphate buffer at $37 \pm 0.5{ }^{\circ} \mathrm{C}$ and $50 \mathrm{rpm}$ rotation. Tablets were withdrawn at 0.5 hour, 1 hour, 2 hour, 4 hour, 6 hour, and 8 hour intervals and soaked with filter paper to absorb excess buffer solution and then weighed again. Percentage swelling of tablets was expressed as the following (Ravindran et al., 2012) :

$$
\text { Swelling index }(\mathrm{Sw})=\frac{[\mathrm{Wt}-\mathrm{Wo}]}{\mathrm{w} 0} \times 100
$$

Where ' $\mathrm{Wt}$ ' is the weight of swollen tablet at time ' $\mathrm{t}$ ' and 'Wo' is the initial weight of tablet.

\section{In Vitro dissolution Study}

In vitro dissolution studies of prepared tablets were performed using USP II dissolution apparatus (Electrolab TDT08L) at $50 \mathrm{rpm}$ in $900 \mathrm{ml}$ of $\mathrm{pH} 6.8$ phosphate buffers at $37 \pm 0.5$
${ }^{0} \mathrm{C}$. The aliquots were collected at specified time intervals $(1,2,3,4,5,6,7,8,12 \mathrm{~h})$ and analyzed at $280 \mathrm{~nm}$ by UV visible Spectrophotometer (Simadzu UV 1800, Japan). Sample volume used for analysis was replaced by equal volumes of fresh dissolution medium pre heated at $37 \pm 0.5{ }^{\circ} \mathrm{C}$ to maintain the sink conditions. The cumulative drug release was then calculated. The study was performed in triplicate.

\section{Drug release Kinetics}

To determine the order and mechanism of Lamivudine release from matrix tablet, the release rate data were fitted to zero order, first-order, Higuchi square root equation and Korsmeyer Peppas equation.

\section{Stability Study}

The stability studies of selected tablet batches were carried out in stability chamber (Remi Instruments, India) kept at $40^{\circ} \mathrm{C}$ and $75 \% \mathrm{RH}$ conditions for three months. The effects of temperature and time on the physical characteristics of the tablet were evaluated for assessing the stability of the prepared formulations.

\section{RESULTS AND DISCUSSION}

Extraction method was employed to produce a higher amount of mucilage from okra. Acetone was used as drying agent as it is able to precipitate out the mucilage from the filtrate. Characterization of the extracted Okra mucilage was performed to determine the physical and chemical attributes of the polymer.

\section{Characterization of Okra mucilage}

Characterization parameters such as solubility study, $\mathrm{pH}$ determination, viscosity study and swelling index of Okra mucilage were calculated and all characterization parameters results are shown in Table 2.

Table 2: Characterization of Okra mucilage.

\begin{tabular}{ll}
\hline Parameters & Results \\
\hline Solubilty & Sparingly soluble in water and insoluble in acetone and \\
& ethanol. \\
pH & $6.7 \pm 0.24$ \\
Viscosity & $247.34 \pm 7.9 \mathrm{cp}$ \\
Swelling ratio & $3.6 \pm 0.9$ \\
\hline \multicolumn{2}{l}{ Data represented Mean \pm S.D, $\mathrm{n}=3}$.
\end{tabular}

\section{Solubility study}

Okra powder was shown to be sparingly soluble in water and insoluble in acetone and ethanol. Okra powder was swelled and formed viscous dispersion when dispersed in water. The slightly soluble behavior of Okra gum is useful in this formulation as the swellable and viscous dispersion represents a strong matrix polymeric system that is able to control the release of Lamivudine.

\section{pH determination}

The $\mathrm{pH}$ of Okra gum was found to be 6.7. Okra gum is known to have maximum viscosity at a neutral $\mathrm{pH}$ range, which 
helps in the retarding effect for the development of sustained release tablet.

Neutral pH also causes minimum irritation to the gastrointestinal tract and is suitable for uncoated tablets (Malviya et al., 2011). Moreover, the neutral $\mathrm{pH}$ of Okra gum will not alter the $\mathrm{pH}$ of Okra tablet that is formulated with Lamivudine.

\section{Viscosity study}

Viscosity of Okra mucilage $1 \%$ solution was found to be $247.34 \mathrm{cp}$. Due to more viscous properties of Okra mucilage, it produces more sticky mass, which helps to slowdown the drug release from tablets and provides better tensile strength (Kalu et al., 2007). The mucilage with a higher degree of stickiness creates a more dense material with heavier cross linkage of molecules, therefore it is able to hold the ingredients in a tablet more efficiently and produce tablets with better retarding effects.

\section{Swelling ratio}

The swelling ratio of mucilage, determined in distilled water, was observed to be $3.6 \pm 0.9$. There was a significant change in swelling by the end of the study, which indicated that the mucilage had excellent swelling properties.

\section{Fourier Transform Infrared Spectroscopy (FTIR)}

FTIR spectra of pure drug, Okra mucilage, and mixture of both are shown in fig.1, fig.2, and fig.3 respectively. The prominent IR absorption peaks of Lamivudine showed at the characteristic peak of the carbonyl group present in the cystidine nucleus at $1650.0 \mathrm{~cm}^{-1}$, a band of peaks at 3328.4 and $3200.2 \mathrm{~cm}^{-1}$ owing to amino and hydroxyl groups. Peaks at 1286.2 and 1160.4 $\mathrm{cm}^{-1}$ owing to asymmetrical and symmetrical stretching of the $\mathrm{C}$ $\mathrm{O}-\mathrm{C}$ system present in the oxathiolane ring. The presence of all the characteristic peaks of drug in the IR spectra of drug polymer mixture indicates no interaction between drug and carrier.



Fig. 1: FTIR spectra of Pure drug (Lamivudine).

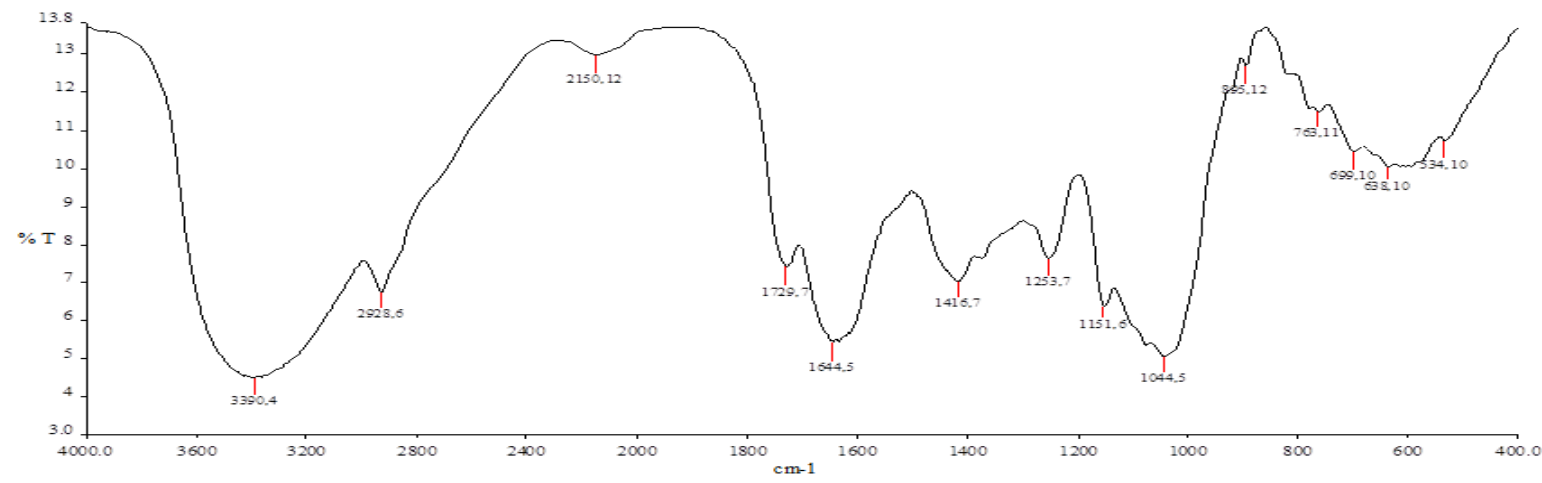

Fig. 2: FTIR spectra of Okra mucilage.

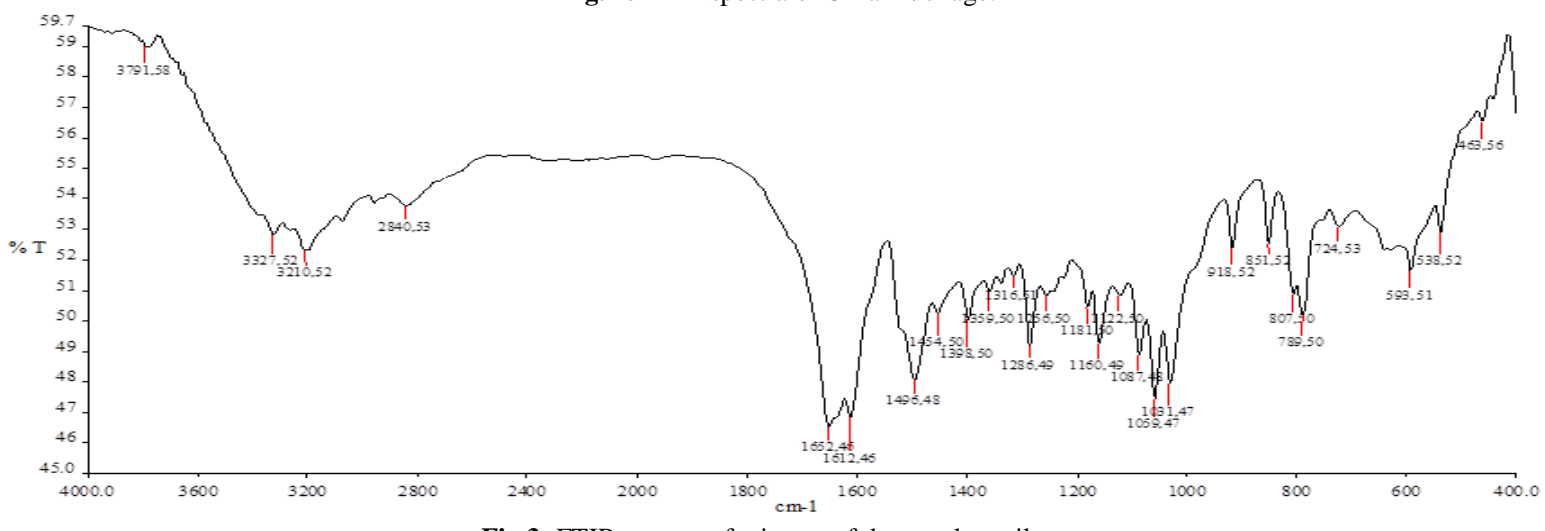

Fig 3: FTIR spectra of mixture of drug and mucilage. 
Table 3: Evaluation of Precompression parameters for mixed blends.

\begin{tabular}{cccccc}
\hline Formulation code & Bulk density $(\mathbf{g m} / \mathbf{c c})$ & Tapped density $(\mathbf{g m} / \mathbf{c c})$ & Angle of repose $\left.\mathbf{(}^{\mathbf{0}}\right)$ & Carr's index(\%) $^{\text {Hausner's ratio }}$ \\
\hline F1 & $0.48 \pm 0.09$ & $0.55 \pm 0.08$ & $27.6 \pm 0.61$ & $12.72 \pm 0.91$ \\
F2 & $0.47 \pm 0.06$ & $0.56 \pm 0.05$ & $28.6 \pm 0.54$ & $1.14 \pm 0.37$ \\
F3 & $0.45 \pm 0.06$ & $0.53 \pm 0.06$ & $27.9 \pm 0.69$ & $15.05 \pm 1.10$ \\
F4 & $0.48 \pm 0.08$ & $0.56 \pm 0.05$ & $27.9 \pm 0.47$ & $14.28 \pm 0.96$ \\
F5 & $0.46 \pm 0.06$ & $0.55 \pm 0.05$ & $26.1 \pm 0.55$ & $16.36 \pm 1.09$ \\
F6 & $0.43 \pm 0.08$ & $0.51 \pm 0.05$ & $25.67 \pm 0.85$ & $1.26 \pm 0.36$ \\
F7 & $0.46 \pm 0.08$ & $0.54 \pm 0.05$ & $27.33 \pm 0.45$ & $14.68 \pm 0.89$ \\
\hline
\end{tabular}

Data represented Mean \pm S.D, $n=3$

Table 4: Evaluation of Post compression parameters of Lamivudine tablet.

\begin{tabular}{|c|c|c|c|c|c|c|c|}
\hline FC & $\begin{array}{c}\text { Mucilage } \\
\text { concentration } \\
(\%)\end{array}$ & $\begin{array}{l}\text { Weight variation } \\
\quad(\mathrm{mg}), \mathbf{n}=\mathbf{2 0}\end{array}$ & $\begin{array}{c}\text { Hardness } \\
\left(\mathrm{kg} / \mathrm{cm}^{2}\right) \\
\mathrm{n}=10\end{array}$ & $\begin{array}{c}\text { Thickness(mm), } \\
\text { n=10 }\end{array}$ & $\begin{array}{c}\text { Friability } \\
(\%), \\
\mathbf{n}=20\end{array}$ & $\begin{array}{l}\text { Swelling index }(\%) \text { after } \\
8 \mathrm{hr}, \mathrm{n}=\mathbf{1 0}\end{array}$ & $\begin{array}{c}\text { Wetting } \\
\text { time(min) } \\
n=10\end{array}$ \\
\hline F1 & 2.5 & $450 \pm 2.6$ & $4.9 \pm 0.92$ & $3.7 \pm 0.1$ & $0.82 \pm 0.11$ & $40.16 \pm 1.1$ & $7.5 \pm 0.5$ \\
\hline F2 & 5 & $449 \pm 1.2$ & $6.1 \pm 0.87$ & $3.8 \pm 0.1$ & $0.61 \pm 0.17$ & $43.12 \pm 1.9$ & $6.7 \pm 0.7$ \\
\hline F3 & 10 & $452 \pm 0.8$ & $6.8 \pm 0.92$ & $4.1 \pm 0.1$ & $0.21 \pm 0.15$ & $44.56 \pm 2.8$ & $5.0 \pm 0.9$ \\
\hline F4 & 15 & $449 \pm 1.2$ & $6.9 \pm 0.86$ & $4.1 \pm 0.1$ & $0.12 \pm 0.09$ & $50.12 \pm 1.7$ & $4.3 \pm 0.5$ \\
\hline F5 & 20 & $447 \pm 1.2$ & $7.2 \pm 0.58$ & $4.1 \pm 0.1$ & $0.13 \pm 0.07$ & $58.61 \pm 2.1$ & $3.9 \pm 0.5$ \\
\hline F6 & 15 & $449 \pm 1.9$ & $5.9 \pm 0.68$ & $3.9 \pm 0.1$ & $0.46 \pm 0.09$ & $76.59 \pm 2.6$ & $4.7 \pm 0.9$ \\
\hline F7 & 15 & $452 \pm 2.8$ & $6.1 \pm 0.89$ & $4.0 \pm 0.1$ & $0.73 \pm 0.04$ & $82.45 \pm 4.7$ & $5.1 \pm 0.8$ \\
\hline
\end{tabular}

Data represented Mean \pm S.D.

\section{Precompression Parameters}

The results of pre compression studies (bulk density, tapped density, angle of repose, Carr's index, etc.) of mixed blends (F1-F5) are given in Table 3. The results of bulk density and tapped density ranged from $0.45 \pm 0.06$ to $0.48 \pm 0.08$ and $0.53 \pm 0.06$ to $0.56 \pm 0.05$, respectively. The results of angle of repose $(26.1 \pm 0.55$ to $28.6 \pm 0.54)$ indicated good flow properties which were further supported by Carr's index $(12.72 \%$ to $16.36 \%)$ and Hausner's ratio data (1.14 to 1.26$)$.

\section{Post compression parameters}

The results of post compression studies are shown in Table 4. All five formulations were uniform in dimensions and exhibited sufficient hardness in the range from $4.9 \pm 0.92$ to $7.2 \pm 0.58$. The friability data $(<1 \%)$ indicated sufficient resistance to abrasion. All the formulation batches passed weight variation test.

The Okra mucilage has a significant impact on swelling and wetting characteristics as seen in batches F1-F5. This enhanced swelling characteristics may be due to the presence of mucilage (Kumar et al., 2009 , Kaur et al., 2014). Okra mucilage showed the highest hardness and lowest friability compared to HPMC and Sodium CMC. This indicates that Okra mucilage produces stronger tablets and is more capable of protecting tablets against capping and lamination (Okoye et al., 2011). It is also a good plasticizer as it forms a smooth film that acts as a coating material for the tablets.

\section{In vitro drug dissolution studies}

In vitro dissolution studies are shown in fig 5 . Dissolution studies were performed using pH 6.8 phosphate buffer. In order to investigate the effect of polymer concentration on drug release profile, different formulations containing various percentages of Abelmoschus esculentus mucilage were used.
The drug release was found to retard more when the concentration of gum increases in the formulation. By increasing the polymer concentration a viscous gel layer is formed resisting to erosion and the diffusion of the drug is controlled primarily by the gel viscosity.

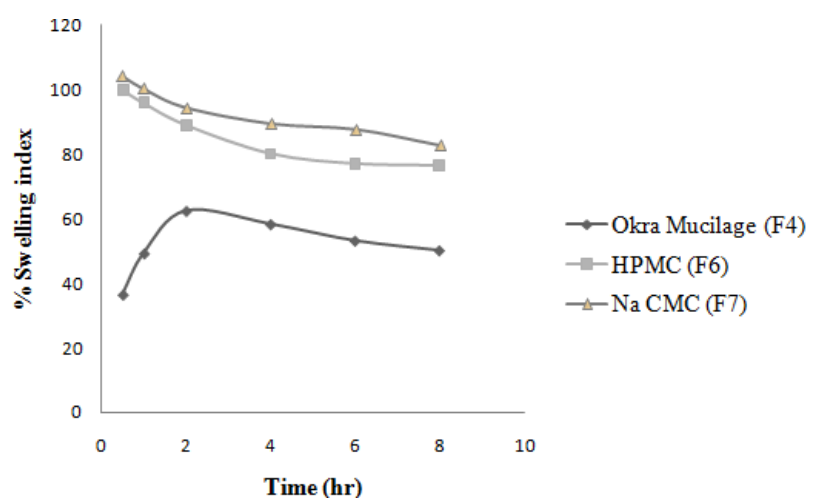

Fig. 4: Swelling index of tablets (F4,F6,F7).

The natural gum is hydrophilic, which is used as an excipient for retarding release of drug in controllable manners up to $12 \mathrm{hrs}$. The formulations F3, F4, and F5 containing mucilage concentrations $(10 \%, 15 \%, 20 \%)$ were able to sustain the drug release up to 12 hrs with percentage drug release $73.45 \%, 69.59 \%$ and $53.99 \%$, respectively which indicate that as the concentration of mucilage increased, drug release was retarded due to increase in the gel strength and formation of gel layer with longer path of diffusion, resulting in reduction in diffusion coefficient of the drug (Zaharuddin et al., 2014). The swelling of tablet occurred due to the formation of the matrix layer by the mucilage around the tablet, enabling it to sustain release of drugs. As the swelling continues, the swollen matrix retains more water until the shear forces in the dissolution medium disentangle the individual polymer chains from the matrix.The formulations F1 and F2 
containing mucilage concentration $2.5 \%$, $5 \%$ were not shown sustained release behavior satisfactorily due to decrease in the gel strength and reduced swelling behavior of the tablet.

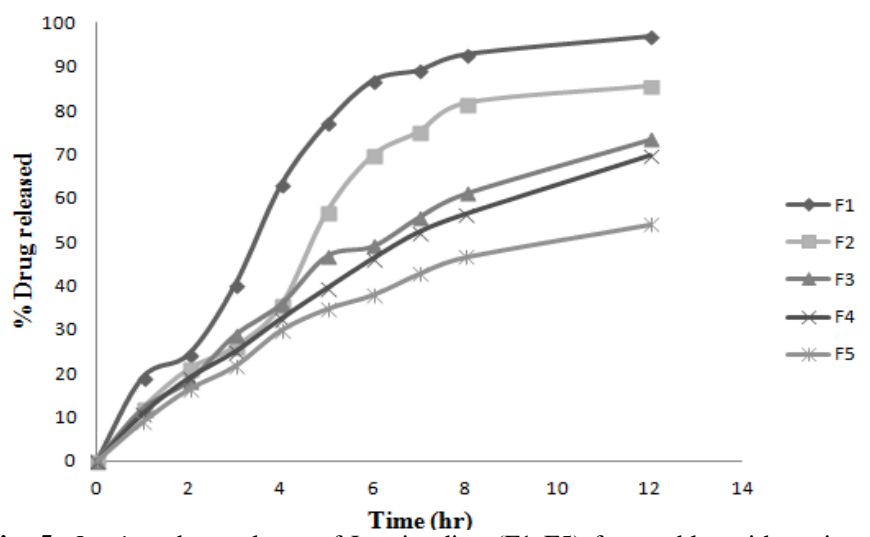

Fig. 5: In vitro drug release of Lamivudine (F1-F5) from tablet with various concentrations of Okra mucilage.

The dissolution profile showed that the drug was released in a moderate and consistent manner up to 12 hours. For the swelling index of tablets that were formulated with HPMC and Sodium CMC, the weight of tablets was seen to decrease at the first hour. This indicates that HPMC and Sodium CMC were not that successful in allowing the tablets to swell for the purpose of controlling the rate of release. This could also be seen from the rapid drug release of tablets formulated with these 2 polymers during the first 4 hours of dissolution studies (Fig. 6).

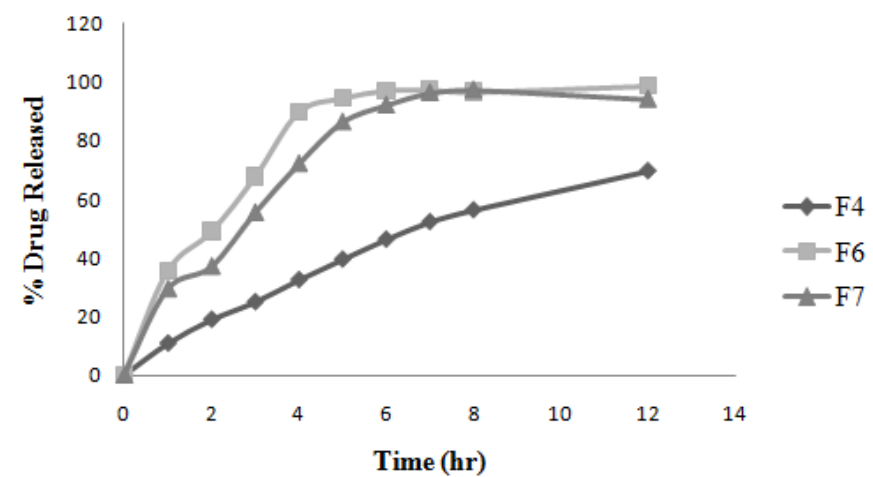

Fig. 6: In vitro drug release of Lamivudine (F4,F6,F7) from tablet with various polymers.

The rate of drug release was observed to be the fastest in tablets formulated with HPMC where it reached $70 \%$ of release in the first 2 hours and released moderately until it reached maximum release at 4 hours. For Sodium CMC tablet, drug release was seen to be rapid for the first 3 hours and they experienced moderate release up to its maximum release at 5 hours. As for Okra tablets, the release was observed to be relatively consistent until it reached maximum release up to 12 hours.

\section{Drug release kinetics}

The drug release kinetics data are shown in Table 5. The in vitro release profiles of drug from all these formulations could be best expressed by Higuchi's equation as the plots showed linearity $\left(\mathrm{R}^{2}=0.901\right.$ to 0.974$)$. To confirm the diffusion mechanism, the data were fitted into Korsmeyer-Peppas equation. The formulations showed good linearity $\left(R^{2}=0.925\right.$ to 0.990$)$ and the ' $\mathrm{n}$ ' values for all the formulations ranged from 0.75 to 0.83 indicating that the release mechanism was non-fickian or anomalous release $(0.45<\mathrm{n}<0.89)$. It can be inferred that the drug release was dependent on both drug diffusion and polymer relaxation.

For tablets with HPMC and Sodium CMC, the ' $n$ ' value of tablets was between 0.29 and 0.39 indicating fickian diffusion principle (Table 5).

The release kinetics studies clearly indicate that the drug release is controlled by diffusion principle. The tablets swell well if immersed in water and the swelling property may control the diffusion of drug from the tablets.

Table 5: Release kinetics of dissolution data of Lamivudine tablet.

\begin{tabular}{ccccccccc}
\hline & \multicolumn{2}{c}{ Zero order } & \multicolumn{2}{c}{ First order } & \multicolumn{2}{c}{ Higuchi } & \multicolumn{2}{c}{$\begin{array}{c}\text { Korsemeyer- } \\
\text { Peppa's }\end{array}$} \\
\cline { 2 - 9 } & K & $\mathbf{R}^{2}$ & $\mathbf{K}$ & $\mathbf{R}^{2}$ & $\mathbf{K}$ & $\mathbf{R}^{2}$ & $\mathbf{n}$ & $\mathbf{R}^{2}$ \\
\hline F1 & 8.889 & 0.829 & -0.138 & 0.971 & 34.01 & 0.916 & 0.77 & 0.925 \\
F2 & 8.143 & 0.889 & -0.081 & 0.940 & 29.84 & 0.901 & 0.83 & 0.955 \\
F3 & 6.274 & 0.943 & -0.049 & 0.943 & 23.11 & 0.967 & 0.78 & 0.980 \\
F4 & 5.904 & 0.964 & -0.043 & 0.947 & 21.55 & 0.966 & 0.78 & 0.990 \\
F5 & 4.602 & 0.926 & -0.029 & 0.956 & 17.18 & 0.974 & 0.75 & 0.986 \\
F6 & 6.951 & 0.634 & -0.125 & 0.764 & 29.95 & 0.885 & 0.29 & 0.820 \\
F7 & 6.329 & 0.524 & -0.127 & 0.765 & 28.65 & 0.811 & 0.39 & 0.865 \\
\hline
\end{tabular}

\section{Stability Study}

Stability studies were carried out using optimized batch F4 as per ICH guidelines for 90 days at accelerated stability condition $\left(40^{\circ} \mathrm{C} / 75 \% \mathrm{RH}\right)$. No remarkable changes were observed in batch F4 (physicochemical properties as well as release profile) as shown in Table 6. This indicates good stability of the formulation even after stressed conditions.

Table 6: Stability study of Optimized formulation (F4) at $40^{\circ} \mathrm{C} / 75 \% \mathrm{RH}$.

\begin{tabular}{lccc}
\hline \multirow{2}{*}{ Parameters } & \multicolumn{3}{c}{ Time } \\
\cline { 2 - 4 } & 1 month & 2 months & 3 months \\
\hline Hardness $\left(\mathrm{kg} / \mathrm{cm}^{2}\right)$ & $6.9 \pm 0.86$ & $6.9 \pm 0.72$ & $6.6 \pm 0.77$ \\
Friability(\%) & $0.12 \pm 0.09$ & $0.12 \pm 0.10$ & $0.12 \pm 0.07$ \\
Swelling index (\%) & $50.12 \pm 1.7$ & $51.87 \pm 2.1$ & $50.45 \pm 1.9$ \\
Wetting time(Min) & $4.3 \pm 0.5$ & $4.5 \pm 0.38$ & $4.3 \pm 0.65$ \\
\% Drug released after 12 & $69.59 \pm 3.9$ & $67.15 \pm 4.2$ & $66.03 \pm 4.6$ \\
hours & & & \\
\hline
\end{tabular}

Data represented Mean \pm S.D, $n=3$

\section{CONCLUSIONS}

Lamivudine sustained release tablets were prepared using Okra mucilage as a sustained release matrix excipient. The Lamivudine tablets were evaluated and the results indicate that as the concentration of mucilage increased, drug release was retarded due to increase in the gel strength and to the formation of the gel layer with longer path of diffusion, resulting in reduction in diffusion coefficient of the drug. It can therefore be concluded that okra mucilage, which is an effective sustained release matrix forming agent may be used for preparation of sustained release Lamivudine tablets. 
Financial support and sponsorship: Nil.

Conflicts of interest: There are no conflicts of interest.

\section{REFERENCES}

Ameena K, dilip C, saraswathi R, Krishnan PN, Sankar C, Simi SP. Isolation of mucilage from hibiscus rosasinesis linn and hablemuschus esculentus linn and studying the binding effect of mucilages. Asian Pacific J Tropic Med, 2010: 539-543.

Bi Y. Preparation and evaluation of a compressed tablet rapidly disintegrating in the oral cavity. Chem Pharm Bull, 1996; 44:2121-2127.

Bi YX. Sunada H, Yonezawa Y, Danjo K. Evaluation of rapidly disintegrating tablets prepared by direct compression method. Drug Dev Ind Pharm, 1999; 25(5): 571-581.

Kalu VD, Odeniyi MA, Jaiyeoba KT. Matrix properties of a new plant gum in controlled drug delivery. Arch Pharm Res, 2007 ;30(7), 884-889.

Kaur L, Bala R, Kanojia N, Nagpal M , Dhingra G A. Formulation development and optimization of fast dissolving tablets of aceclofenac using natural superdisintegrant. ISRN Pharmaceutics, 2014; 2014: 1-10.

Kumar R, Patil S, Patil MB, Patil SR, Paschapur MS. Isolation and evaluation of disintegrant properties of fenugreek seed mucilage. Int $\mathrm{J}$ Pharm Tech Res, 2009; 1:982-996.

Malviya R. Extraction characterization and evaluation of selected mucilage as pharmaceutical excipients. Polimery w Medycynie, 2011; 41: 39-44.

Modasiya MK, Lala II, Prajapati BG, Patel VM, Shah DA. Design and characterization of fast disintegrating tablets of piroxicam. Int J Pharm Tech Res, 2009;1: 353-357.

Moyle G. Clinical manifestations and management of antiretroviral nucleoside analog-related mitochondrial toxicity. Clin Ther, 2000; 22:911-936.
Okoye EI, Onyekweli AO, Kunle OO. Okra gum an economic choice for the amelioration of capping and lamination in tablets. Annals Biological Res, 2011; 2:30-42.

Punna RR, Sindhura G, Saha. RN.Design and study of lamivudine oral controlled release tablets. AAPS PharmSciTech, 2007; 8: E1-E9.

Ravindran VK, Vasa S, Subadhra S, Banji D, Banji O, Rao YM. Comparative study of mucoadhesive polymers carbopol 974P and sodium carboxymethyl cellulose for single unit dosage of imatinib mesylate." Malay J Pharm Sci, 2012; 10(1),61-77.

Singh K, Kumar A, Langyan N, Ahuja M. Evaluation of Mimosa pudica seed mucilage as sustained release excipient. AAPS Pharm Sci Tech, 2009; 10:1121-1127.

Srinivas K, Prakash K, Kiran HR, Prasad PM, Rao MEB. Study of Ocimum basilicum and Plantago ovata as disintegrants in the formulation of dispersible tablets. Indian J Pharm Sci, 2003; 65:180-183.

Zaharuddin ND, Noordin MI, Kadivar A. The use of hibiscus esculentus (Okra) gum in sustaining the release of propranolol hydrochloride in a solid oral dosage form. BioMed Res Int, 2014; 2014: $1-8$

\section{How to cite this article:}

Palei NN, Mamidi SK, Rajangam J. Formulation and evaluation of lamivudine sustained release tablet using okra mucilage. J App Pharm Sci, 2016; 6 (09): 069-075. 